\title{
Research on Order-Inventory Transshipment Mechanism in Dual-Channel Distribution Supply Chain
}

\author{
Min Shi \\ School of Management, Jinan University, Guangzhou, China \\ Email: sddm459@163.com
}

How to cite this paper: Shi, M. (2019) Research on Order-Inventory Transshipment Mechanism in Dual-Channel Distribution Supply Chain. Open Journal of Business and Management, 7, 1120-1130. https://doi.org/10.4236/ojbm.2019.73077

Received: April 16, 2019

Accepted: May 5, 2019

Published: May 8, 2019

Copyright $\odot 2019$ by author(s) and Scientific Research Publishing Inc. This work is licensed under the Creative Commons Attribution International License (CC BY 4.0).

http://creativecommons.org/licenses/by/4.0/

\section{(c) (i) Open Access}

\begin{abstract}
The development of e-commerce has prompted traditional enterprises to open up online channels and form a dual-channel sales model. The increase in the number of channels has led to an increase in the number of orders, so how to properly and effectively match the order with the inventory will test the operational capabilities of the enterprise. Based on this practical problem, this thesis considers a two-echelon distribution system with online and offline dual-channel sales, which consists of one group node $(G)$ and multiple distribution nodes $(D)$. When online orders are not fully satisfied, we propose an operation mechanism of transporting inventory to online orders through offline inventory. An optimal decision model is constructed by using the Analysis Target Cascading (ATC). Finally, the model is simulated and analyzed with a specific case. The results show that the ATC method and the transshipment mechanism are effective.
\end{abstract}

\section{Keywords}

Dual-Channel, Distribution Supply Chain, Transshipment Mechanism, ATC

\section{Introduction}

The convenience and low cost of online retailing make e-commerce develop with each passing day and penetrate deeply into various industries in various fields. In order to maintain their own development and expand the profit growth space, more and more companies, especially traditional distribution companies, have developed and implemented their own "Internet+" action plans, opened up e-commerce channels, and tried to go online and offline. The distribution channels are effectively integrated to meet the changing market demand of the new 
era, forming a dual-channel distribution model. Chiang et al. [1] also demonstrated from an academic perspective that the increase in channels has brought many benefits to enterprises. The increase in channels leads to a surge in the number of orders, and the reasonable and effective matching of order-inventories affects the operating costs of enterprises, which in turn affects the operational capabilities of enterprises. Therefore, this thesis intends to solve the order for different echelons, different nodes and different channels existing in the dual channel marketing mode in the "distribution-inventory" network about how to obtain the optimal transshipment decision through the transshipment strategy and relevant methods to make the overall cost of the group enterprise optimal.

Referring to the development experience of China and foreign countries, dual-channel marketing has become a necessary means for enterprises in the mature e-commerce today, and our study will also be an important part of the supply chain operation process. Therefore, the study of this thesis has important theoretical and practical contributions. In terms of theoretical contribution, this thesis uses the Analysis Target Cascading (ATC) to solve the problem, which enriches the solution method of supply chain inventory problem. In terms of actual contribution, this thesis has developed an effective order-inventory transfer mechanism to improve the operational efficiency of the supply chain and provide some practical guidance for dual-channel enterprises. However, because this thesis considers the order-inventory allocation process under the inventory structure of a two-echelon distribution network with the same price, single product and dual-channel sales, there are some limitations in its application.

The rest of the thesis is organized as follows: Part 2 is literature review. Part 3 is a description of the problem, analyzing the structure of the dual-channel distribution-type supply chain and proposing an order satisfaction mechanism. Part 4 establishes an ATC solution model based on the order satisfaction mechanism proposed in Part 3. Part 5 uses simulation and analysis to verify the effectiveness of the proposed mechanism and the method used. Part 6 summarizes the article and points out future research directions.

\section{Literature Review}

The research literature relevant to the work in this thesis falls into two disparate streams: inventory transshipment and Analysis Target Cascading (ATC).

Orders need immediate response to inventory, and inventory transshipment can be divided into order-driven emergency transshipment and demand forecast-driven transshipment. Because this thesis mainly studies emergency transshipment, the preventive transshipment is not detailed, see Paterson [2]. For multipoint transshipments, Lee (1987) [3] used a benchmark inventory strategy for a multipoint inventory model with presence scheduling to investigate a two-echelon transshipment system for a single repairable spare. Assaxter (1999) [4] improved Sherbrooke's model so that emergency transshipments can be made by external suppliers. Wong et al. (2005) [5] formulated a two-node inventory of multiple 
types and multi-node spare parts under the constraints of time to allow the use of emergency transshipment mechanism when local stocks are out of stock. For the study of multi-echelon transshipment, Shao et al. (2016) [6] studied the impact of two-echelon decentralized decision-making supply chain inventory transshipment on the profit of all parties in the supply chain, and determined the optimal decision-making echelon of manufacturers and retailers. For distributed transshipment, in the general distributed inventory system, the inventory transshipment model usually assumes that each partial inventory order requirement is coordinated by a central agent [7]. Nonås et al. (2007) [8] modeled and analyzed the single-cycle centralized control distributed inventory system to obtain optimal inventory and transshipment strategies for three or four inventory points. The problem of transshipment to distributed inventory systems is also Herer \& Tzur (2003) [9], Özdemir (2006) [10], Olsson (2009) [11].

Since the dual-channel multi-echelon distribution supply chain is a complex system with multiple echelons, this thesis uses the Analysis Target Cascading (ATC) to solve the hierarchical problem. This method is one of the Multidisciplinary Design Optimization (MDO) methods. Since the development of MDO in the 1980s, MDO has been widely used in various engineering and management problem [12]. The ATC has the advantages of parallel optimization, unrestricted number of echelons, and strict convergence proof for solving complex large system optimizations that can be decomposed into hierarchical architectures. QU (2008) [13] used ATC to study the problem of assembly supply chain optimization configuration, and published several ATC solutions to the optimization problem of assembly supply chain [14] [15]. Huang et al. (2008) [16] used the extended ATC to solve the problem of supply chain optimization configuration multidisciplinary distributed optimization, in order to improve the overall optimization efficiency while retaining the supplier's decision-making power.

\section{Problem Description}

\subsection{Structure Model of Dual-Channel Distribution Supply Chain}

This thesis considers a two-echelon distribution system for dual-channel multi-echelon distribution of online and offline sales the same products. The Group $(G)$ node is the highest decision node, does not participate in direct sales, does not store inventory, and is responsible for the optimal transshipment of online orders and offline orders that cannot be satisfied. The Distribution $(D)$ node not only has a warehousing function, but also a distribution function, which meets the end-customer offline retail and online order.

\subsection{Order Satisfaction Mechanism of Dual-Channel Distribution Supply Chain}

For the two-channel enterprise, the order is mainly wired online order and offline order. For the satisfaction of online orders, the group node is mainly coor- 
dinated in chronological order, and the online inventory of each sub-node is used preferentially. If it is not satisfied, it is supplemented by offline inventory at the same node. This thesis mainly studies this mode. For the satisfaction of offline orders, it refers to the demand for store consumption, so first meet the offline inventory. If it is not met, it cannot be directly used to meet the online inventory. It is necessary to submit the node for global coordination.

\section{Model}

\subsection{ATC Introduction}

At the end of the last century, ATC was widely used in the optimization of complex systems, such as automotive optimization and optimization of aerospace structures. The principle is to optimize the system by stratifying the complex system, then transforming the target into a multi-echelon structure, and optimizing the subsystem through the superior parent system to optimize the whole system. The optimization criterion of the ATC method is that each element in the hierarchy will minimize the deviation of the shared variable between the father and the child. When all the deviations are within the allowable range, the system can reach the optimal state. A detailed introduction to ATC can be found in the literature [13]. The ATC method solves the complex system in five steps, that is, echeloning the complex system according to the target, aspect or model echeloning method. Determine shared variables at the parent-child echelon and subsystem echelon. Establish a hierarchy of ATC models. Choose a global coordinated solution mechanism. Select the coordination method between parent subsystems.

\subsection{ATC Model}

The required symbols for the model are described in Table 1.

Table 1. Description of Symbols.

\begin{tabular}{|c|c|c|c|}
\hline Symbol & Description & Symbol & Description \\
\hline$G$ & group node & $D$ & distribution node \\
\hline$i$ & echelon, $i=G, D$ & $j$ & nodes, $\quad j=1,2,3, \cdots, N$ \\
\hline$m$ & product weight & $p$ & product transportation unit price \\
\hline$c$ & unit cost & $s$ & transportation distance \\
\hline$d_{e i j}$ & $\begin{array}{l}\text { quantity of online order assigned to } \\
\text { echelon } i \text { node } j\end{array}$ & $d_{s i j}$ & $\begin{array}{l}\text { quantity of offline order assigned to } \\
\text { echelon } i \text { node } j\end{array}$ \\
\hline$q_{e i j}$ & $\begin{array}{l}\text { quantity of online available inventory } \\
\text { of echelon } i \text { node } j\end{array}$ & $q_{s i j}$ & $\begin{array}{c}\text { quantity of offline available inventory } \\
\text { of echelon } i \text { node } j\end{array}$ \\
\hline$T C_{i j}$ & total cost of echelon $i$ node $j$ & $T$ & target cost of ench \\
\hline$S T_{i j}$ & Service time of echelon $i$ node $j$ & $S T$ & target service time \\
\hline$\omega_{i j}^{T C}, \omega_{i j}^{S T}$ & $\begin{array}{l}\text { target weight factor } \\
\text { of echelon } i \text { node } j\end{array}$ & $\varepsilon_{i j}^{T C}, \varepsilon_{i j}^{S T}$ & $\begin{array}{l}\text { variable deviation tolerance of } \\
\text { echelon } i \text { node } j\end{array}$ \\
\hline
\end{tabular}


According to the idea of ATC construction model, this thesis divides the distribution system into two echelon of group and distribution nodes, and its structure corresponds to the model distribution of ATC as shown in Figure 1 .

Next, we will construct the ATC solution model for group nodes and distribution nodes with the objective of minimizing cost $T C$ and service time $S T$, and the decision variables are order transshipment quantity $d$ and service time $S T . S T$ is the key variable among ATC model levels.

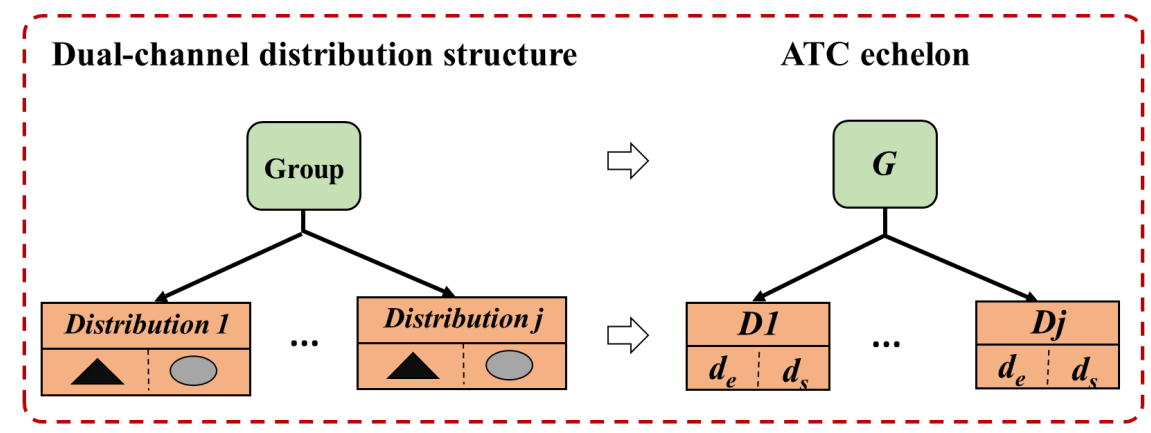

Figure 1. Dual channel structure \& ATC echelon diagram.

\subsubsection{ATC Model of Group Node $(G)$}

$$
\begin{aligned}
& \min \omega_{G}^{T C}\left(T C_{G}-T\right)^{2}+\omega_{G}^{S T}\left(S T_{G}-S T\right)^{2}+\varepsilon_{G}^{T C}+\varepsilon_{G}^{S T} \\
& T C_{G}=c_{f 1}+T C_{D 1}+T C_{D 2}+T C_{D 3} \\
& S T_{G}=\max \left(S T_{i j}\right) \quad(i=1,2,3 ; j=1, \cdots, n) \\
& S T_{V 1}-S T \geq 0, S T_{V 1}, S T \geq 0 \text { and int. } \\
& \left(S T_{v 1}-\max \left\{S T_{D 1}^{3}, S T_{D 2}^{3}, S T_{D 3}^{3}\right\}\right)^{2} \leq \varepsilon_{G}^{S T} \\
& \left(T C_{D, 1}-T C_{D, 1}^{3}\right)^{2} \leq \varepsilon_{G 1}^{T C},\left(T C_{D 2}-T C_{D 2}^{3}\right)^{2} \leq \varepsilon_{G 2}^{T C},\left(T C_{D 3}-T C_{D 3}^{3}\right)^{2} \leq \varepsilon_{G 3}^{T C} \\
& T C_{D 1}, T C_{D 2}, T C_{D 3} \geq 0 \\
& d_{e i j} \leq \sum_{i, j=1}^{n} q_{e i j}+q_{s i j}, d_{s i j} \leq \sum_{i, j=1}^{n} q_{s i j} \\
& d_{e i j} \beta+d_{s i j}(1-\beta)=d_{G}, \quad \beta= \begin{cases}1, & \text { online-order } \\
0, & \text { offline-order }\end{cases} \\
& \frac{q_{s i j}}{q_{e i j}}=1
\end{aligned}
$$


In the ATC model of group node, Formula (1) is the objective function of group node minimization, which is mainly composed of cost and service time, cost consistency deviation and service time consistency deviation. Formula (2) is the total cost of the node, because the group node does not hold inventory, so only the sum of transaction cost and the total cost of the downstream node $T C_{D j}$. Formula (3) is the coupling relationship between upper and lower levels of service time. Formula (4)-(7) denotes the selection of nodes, which refers to the input constraints of the current node's service time and the response cost constraints of the lower nodes. Formula (8)-(9) is order proportional constraint, that is, order-driven inventory transshipment. Formula (10) denotes the ratio of online and offline inventory set by nodes.

\subsubsection{ATC Model of Distribution Node (D)}

$$
\begin{aligned}
& \min \omega_{D 1}^{T C}\left(T C_{D 1}-T C\right)^{2}+\omega_{D 1}^{S T}\left(S T_{D 1}-S T\right)^{2}+\varepsilon_{D j}^{T C}+\varepsilon_{D 1}^{S T} \\
& T C_{D 1}=c_{D 1}\left[d_{e D j} \beta+d_{s D j}(1-\beta)\right]+m\left[d_{e D j} \beta+d_{s D j}(1-\beta)\right] p_{D 1} s_{D 1}+T C_{R 1}+T C_{R 2} \\
& S T_{D 1}=\max \left(S T_{i j}\right) \quad(i=2,3 ; j=1,2, \cdots, n) \\
& \sum_{S O_{D 1} \in S_{D 1}} c_{D 1 S O_{D 1}} y_{D 1, S O_{D 1}}-c_{D 1 S O_{D 1}}=0 \\
& \sum_{S O_{D 1} \in S_{D 1}} p_{D 1 S O_{D 1}} y_{D 1, S O_{D 1}}-p_{D 1 S O_{D 1}}=0 \\
& y_{D 1, S O_{D 1}}=\left\{\begin{array}{ll}
1 & \text { selected } \\
0 & \text { not selected }
\end{array} \text { and } \sum_{S O_{D 1} \in S_{D 1}} y_{D 1, S O_{D 1}}=1\right. \\
& Z_{D j}=\left\{\begin{array}{ll}
0 & \text { not selected, } d_{D j}=0 \\
1 & \text { selected, } d_{D j} \neq 0
\end{array} \quad(j=1,2)\right. \\
& d_{e D}=\sum_{j=1}^{2} z_{D j} d_{e D j}, d_{s D}=\sum_{j=1}^{2} z_{D j} d_{s D j} \\
& 1 \leq \sum z_{D j} \leq 2 \\
& S T_{V D 1}-S T_{D 1} \geq 0, S T_{V D 1}, S T_{D 1} \geq 0 \text { and int. } \\
& T C_{S 1}, T C_{S 2} \geq 0 \\
& \left(T C_{S, 1}-T C_{S, 1}^{4}\right)^{2} \leq \varepsilon_{D 1}^{T C},\left(T C_{S, 2}-T C_{S, 2}^{4}\right)^{2} \leq \varepsilon_{D 2}^{T C} \\
& \left(S T_{v D 1}-\max \left\{S T_{S 1}^{4}, S T_{S 2}^{4}\right\}\right)^{2} \leq \varepsilon_{S 1}^{S T} \\
& d_{e D j} \leq q_{e D j}+q_{s D j}, d_{s D j} \leq q_{s D j} \\
& d_{e D j} \beta+d_{s D j}(1-\beta)=d_{D j}, \beta= \begin{cases}1, & \text { online-order } \\
0, & \text { offline-order }\end{cases} \\
& \frac{q_{s D j}}{q_{e D j}}=1
\end{aligned}
$$


The model of distribution node is similar to that of group node. The concrete formula can be seen as group node. Formula (12) denotes the transportation cost, including the quantity, price, distance and weight of goods, taking into account the transshipment cost. Formulas (14) and (15) indicate that only one node is selected.

\subsection{Solution Mechanism}

The solution of ATC model involves two aspects: the first is to determine the global coordination mechanism of ATC, that is, the convergence order of ATC; the second is to determine the local optimization of each sub-element in each layer model. As described in document [13], this thesis chooses the weight updating method as the global coordination strategy. In recent years, genetic algorithm has been more and more widely used in the field of supply chain optimization, so this thesis also chooses genetic algorithm for local optimization of hierarchical sub-models. Among them, the chromosomes of each node are coded by the method of sequence combination. The fitness function chooses the objective function. The selection operator is determined by the combination of elite selection and fitness ratio. The crossover operator is generated by crossover of two points.

\section{Numerical Study}

Based on the background of a red wine trading enterprise in China, this thesis selected some nodes for numerical study to verify the validity of the ATC solution method. The enterprise has two distribution modes: physical stores and e-commerce sales. The dual-channel distribution network in this case consists of four nodes, one group node and three distribution nodes. Parameter settings are shown in Table 2 and Table 3.

Because group nodes undertake online orders through commercial platforms, when the inventory on selected nodes cannot meet the order demand, the off-line inventory is used to replenish, and if all cannot be met, the global transshipment is carried out. The effectiveness of ATC in solving such problems is tested by referring to the results of manual processing. The following is a comparison of the results of manual processing and ATC coordination when orders are 17, 34 and 51, respectively, as shown in Table 4.

It can be shown from Table 4 that the total cost and maximum service time of the ATC coordination method are lower than the results of manual processing. It can be seen that the ATC optimization coordination method has more obvious advantages than the manual processing method in the target optimization solution result. It proves that it has stronger effectiveness and adaptability to the distribution dynamic transshipment of hierarchical structure.

We also conducted a sensitivity analysis of the impact of order volume on cost, mainly including the impact of order volume on total cost and the impact on unit cost. The results can be seen in Figure 2. 
Table 2. Case parameters value.

\begin{tabular}{ccccccc}
\hline \multirow{2}{*}{ Node } & SO & $\boldsymbol{d}$ & $\boldsymbol{c}$ & $\boldsymbol{c}$ & \multicolumn{2}{c}{$\boldsymbol{q}$} \\
\cline { 5 - 7 } G & 1 & - & - & online & offline \\
\hline D1 & 1 & $\leq 4$ & 100.00 & 2.00 & & \\
& 2 & $>4$ & 94.50 & 1.30 & 31 & 21 \\
D2 & 1 & $\leq 4$ & 100.00 & 1.90 & & \\
& 2 & $>4$ & 97.00 & 1.80 & 3 & 24 \\
D3 & 1 & $\leq 4$ & 100.00 & 2.10 & & \\
& 2 & $>4$ & 95.78 & 1.50 & 10 & 10 \\
\hline
\end{tabular}

Table 3. Initial parameter values of ATC optimization.

\begin{tabular}{cc}
\hline Parameter & Initial Parameter Values \\
\hline node $G$ cost response $T C_{G}$ & $T C_{D 1}=521 ; T C_{D 2}=676 ; T C_{D 2}=665$ \\
node $G$ service time response $S T_{G}$ & $S T_{D 1}=15 ; S T_{D 2}=10 ; S T_{D 2}=8$ \\
target cost $T$ & 0 \\
target service time $S T$ & 0 \\
target weight $\omega_{i j}^{T C}, \omega_{i j}^{S T}$ & {$[1,1]$} \\
variable deviation tolerance $\varepsilon_{i j}^{T C}, \varepsilon_{i j}^{S T}$ & {$[2,0.5]$} \\
maximum number of iterations & 100 \\
\hline
\end{tabular}

Table 4. Results of manual and ATC coordination under different order quantities.

\begin{tabular}{|c|c|c|c|c|c|c|c|c|c|}
\hline \multirow{2}{*}{$\begin{array}{c}\text { Quantity of } \\
\text { Order }\end{array}$} & \multirow{2}{*}{ Node } & \multicolumn{4}{|c|}{ Results of manual } & \multicolumn{4}{|c|}{ Results of ATC coordination } \\
\hline & & SO & $T C$ & $S T$ & $Q O$ & SO & $T C$ & $S T$ & $Q O$ \\
\hline \multirow{4}{*}{17} & $G$ & - & - & - & - & - & - & - & - \\
\hline & $D 1$ & 2 & 1838.6 & 4 & 17 & 2 & 1342 & 3 & 13 \\
\hline & $D 2$ & - & - & - & - & 1 & 431 & 2 & 4 \\
\hline & $D 3$ & - & - & - & - & 2 & - & - & - \\
\hline \multicolumn{2}{|l|}{ Total } & - & 1838.6 & - & - & - & 1773 & - & - \\
\hline \multicolumn{2}{|c|}{ Maximum } & - & - & 4 & - & - & - & 3 & - \\
\hline \multirow{4}{*}{34} & G & - & - & - & - & - & - & - & - \\
\hline & $D 1$ & - & - & - & - & 1 & 102 & 5 & 1 \\
\hline & $D 2$ & 2 & 648.4 & 7 & 6 & 2 & 3139.8 & 1 & 31 \\
\hline & $D 3$ & 2 & 3055.5 & 1 & 28 & 1 & 101 & 6 & 1 \\
\hline \multicolumn{2}{|l|}{ Total } & - & 3703.9 & - & - & - & 3342.8 & - & - \\
\hline \multicolumn{2}{|c|}{ Maximum } & - & - & 7 & - & - & - & 6 & - \\
\hline \multirow{4}{*}{51} & $G$ & - & - & - & - & - & - & - & - \\
\hline & $D 1$ & 2 & 4255.8 & 12 & 39 & 2 & 1032.6 & 10 & 10 \\
\hline & $D 2$ & 2 & 1316 & 5 & 12 & 2 & 1300 & 5 & 13 \\
\hline & $D 3$ & - & - & - & - & 1 & 3021.2 & 7 & 28 \\
\hline \multicolumn{2}{|l|}{ Total } & - & 5571.8 & - & - & - & 5353.8 & - & - \\
\hline \multicolumn{2}{|c|}{ Maximum } & - & - & 12 & - & - & - & 10 & - \\
\hline
\end{tabular}




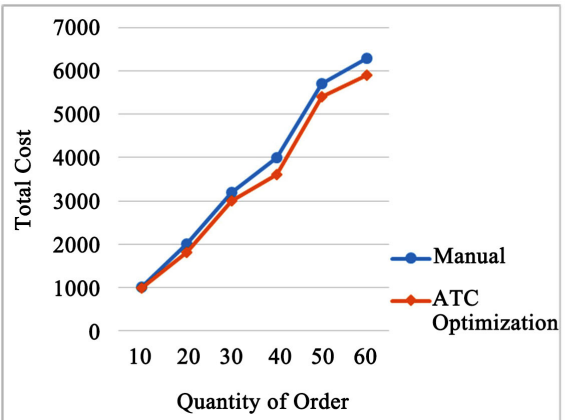

(a)

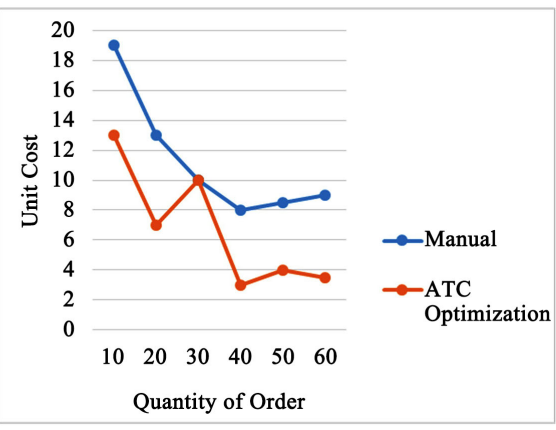

(b)

Figure 2. Results of the impact of order quantity on cost. (a) The effect of the order quantity on the total cost; (b) The effect of the order quantity on the unit cost.

Figure 2(a) shows that the relationship between the order quantity and the total cost is close to positive correlation, and the ATC optimization method has better characteristics than the manual processing method under the same conditions. Figure 2(b) shows that the relationship between the order quantity and the unit cost is approximately inversely proportional. That is, as the order quantity increases, the unit cost decreases overall, and the rate of decline gradually becomes smaller, and finally stabilizes. Under the same conditions, the ATC coordination optimization curve has small fluctuations, and the unit cost will slightly rebound when the order quantity exceeds a certain value, but overall it has better characteristics than the traditional manual processing method.

In summary, the ATC coordination method under the online and offline dual channels is better than the manual method.

\section{Conclusion}

This thesis studies a two-echelon supply chain network consisting of one group node and multiple distribution nodes with a dual-channel sales model, and proposes an order processing strategy that uses offline inventory to transport and replenish when online inventory is out of stock. The dual-channel inventory dynamic transshipment optimization decision model is solved by ATC. And through sensitivity analysis of important parameters, we can see that ATC optimization can achieve more cost-saving results than manual processing results. At the same time, the increase in online orders has led to an increase in total costs and a decrease in unit costs. However, the unit cost will rebound slightly when the order quantity exceeds a certain value. In the future, we will expand the research from the perspective of multi-product and multi-cycle, so that the research is more in line with the actual situation.

\section{Conflicts of Interest}

The author declares no conflicts of interest regarding the publication of this paper. 


\section{References}

[1] Chiang, W.Y.K., Chhajed, D. and Hess, J.D. (2003) Direct Marketing, Indirect Profits: A Strategic Analysis of Dual-Channel Supply-Chain Design. Management Science, 49, 1-20. https://doi.org/10.1287/mnsc.49.1.1.12749

[2] Paterson, C., Kiesmüller, G., Teunter, R., et al. (2011) Inventory Models with Lateral Transshipments: A Review. European Journal of Operational Research, 210, 125-136. https://doi.org/10.1016/j.ejor.2010.05.048

[3] Lee, H.L. (1987) A Multi-Echelon Inventory Model for Repairable Items with Emergency Lateral Transshipments. Management Science, 33, 1302-1316. https://doi.org/10.1287/mnsc.33.10.1302

[4] Alfredsson, P.P. and Verrijdt, J.J. (1999) Modeling Emergency Supply Flexibility in a Two-Echelon Inventory System. Management Science, 45, 1416-1431. https://doi.org/10.1287/mnsc.45.10.1416

[5] Wong, H., Houtum, G.J.V., Cattrysse, D., et al. (2005) Simple, Efficient Heuristics for Multi-Item Multi-Location Spare Parts Systems with Lateral Transshipments and Waiting Time Constraints. Journal of the Operational Research Society, 56, 1419-1430. https://doi.org/10.1057/palgrave.jors.2601952

[6] Jing, S. and School, B. (2016) Impact of Transshipment on a Decentralized Supply Chain. Chinese Journal of Management Science, 7, 76-81

[7] Zeng, L.M. and Han, R.Z. (2010) Discussion and Simulation of Distributed Inventory System Strategy. Journal of System Simulation, 11, 2528-2531.

[8] Non, S.L.M. and Rnsten, J.K. (2007) Optimal Solutions in the Multi-Location Inventory System with Transshipments. Journal of Mathematical Modelling and Algorithms in Operations Research, 6, 47-75. https://doi.org/10.1007/s10852-006-9049-y

[9] Herer, Y.T. and Tzur, M. (2003) Optimal and Heuristic Algorithms for the Multi-Location Dynamic Transshipment Problem with Fixed Transshipment Costs. IIE Transactions, 35, 419-432. https://doi.org/10.1080/07408170304389

[10] Ozdemir, D., Yucesan, E. and Herer, Y.T. (2006) Multi-Location Transshipment Problem with Capacitated Production and Lost Sales. Proceedings of the 2006 Winter Simulation Conference, Monterey, 3-6 December 2006, 1470-1476. https://doi.org/10.1109/WSC.2006.322915

[11] Olsson, F. (2009) Optimal Policies for Inventory Systems with Lateral Transshipments. International Journal of Production Economics, 118, 175-184. https://doi.org/10.1016/j.ijpe.2008.08.021

[12] Sobieszczanski-Sobieski, J. (1982) A Linear Decomposition Method for Large Optimization Problems. Blueprint for Development. Acta Anatomica, 113, 53-60.

[13] Qu, T. (2008) Analytical Target Cascading for Decentralized Supply Chain Configuration. The University of Hong Kong, Hong Kong.

[14] Qu, T., Huang, G.Q., Cung, V., et al. (2010) Optimal Configuration of Assembly Supply Chains Using Analytical Target Cascading. International Journal of Production Research, 48, 6883-6907. https://doi.org/10.1080/00207540903307631

[15] Qu, T., Huang, G., Chen, X., et al. (2009) Extending Analytical Target Cascading for Optimal Supply Chain Network Configuration of a Product Family. International Journal of Computer Integrated Manufacturing, 22, 1012-1023. https://doi.org/10.1080/09511920802616807

[16] Huang, G.Q. and Qu, T. (2008) Extending Analytical Target Cascading for Optimal 
Configuration of Supply Chains with Alternative Autonomous Suppliers. International Journal of Production Economics, 115, 39-54.

https://doi.org/10.1016/j.ijpe.2008.04.008 